Wen Bin, Xu Li-Hua, Liu Na and Ni Zhong-Hai*

\title{
Crystal structure and photochemical property of 1,8-bis(p-tolylthio)pyrene, $\mathrm{C}_{30} \mathrm{H}_{22} \mathrm{~S}_{2}$
}

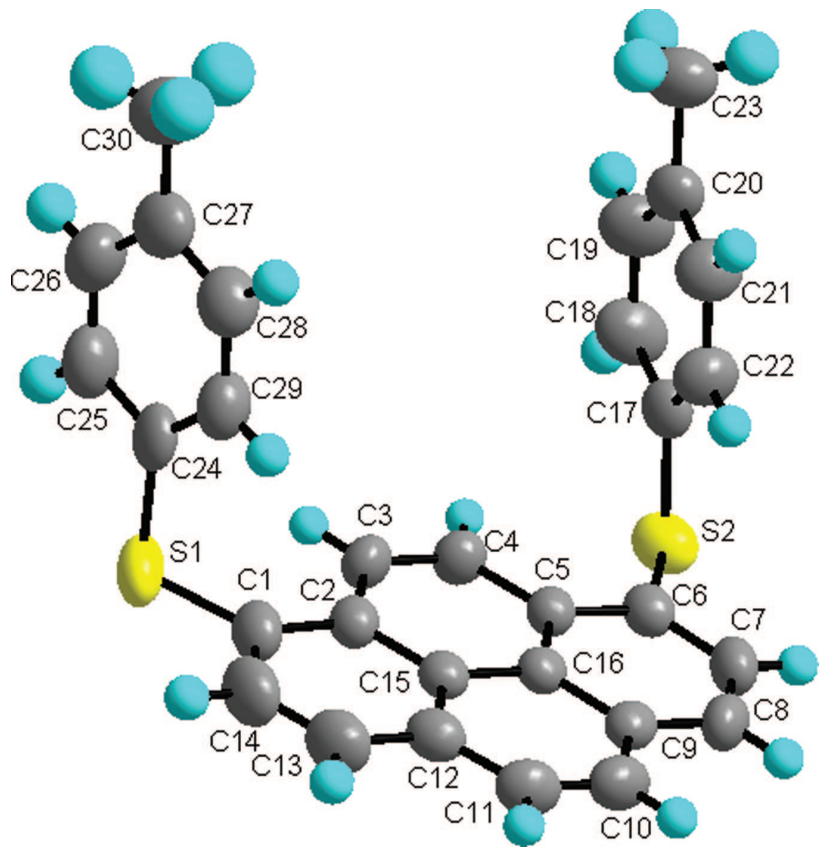

https://doi.org/10.1515/ncrs-2018-0318

Received August 20, 2018; accepted November 5, 2018; available online December 22, 2018

\footnotetext{
Abstract

$\mathrm{C}_{30} \mathrm{H}_{22} \mathrm{~S}_{2}$, triclinic, $P \overline{1}$ (no. 2), $a=7.604(4) \AA, b=11.556(5) \AA$, $c=13.090(7) \AA, \alpha=93.964(8)^{\circ}, \beta=93.209(8)^{\circ}, \gamma=90.619(9)^{\circ}$, $V=1145.7(10) \AA^{3}, Z=2, R_{\mathrm{gt}}(F)=0.0497, w R_{\mathrm{ref}}\left(F^{2}\right)=0.1295$, $T=296(2) \mathrm{K}$.
}

\section{CCDC no.: 1877125}

The crystal structure is shown in the figure. Tables 1 and 2 contain details on crystal structure and measurement condi-

\footnotetext{
*Corresponding author: Ni Zhong-Hai, School of Chemical Engineering and Technology, China University of Mining and Technology, Xuzhou 221116 Jiangsu Province, P.R. China, e-mail: nizhonghai@cumt.edu.cn

Wen Bin and Liu Na: Shandong Provincial Key Laboratory of Oilfield Produced Water Treatment and Environmental Pollution Control (Sinopec Petroleum Engineering Corporation), Dongying 257026 Shandong Province, P.R. China

Xu Li-Hua: School of Chemical Engineering and Technology, China University of Mining and Technology, Xuzhou 221116 Jiangsu Province, P.R. China
}

Table 1: Data collection and handling.

\begin{tabular}{ll}
\hline Crystal: & Strip, block \\
Size: & $0.16 \times 0.12 \times 0.06 \mathrm{~mm}$ \\
Wavelength: & Mo $K \alpha$ radiation $(0.71073 \AA)$ \\
$\mu:$ & $0.25 \mathrm{~mm}^{-1}$ \\
Diffractometer, scan mode: & Bruker APEX-II, $\varphi$ and $\omega$-scans \\
$\theta_{\text {max }}$, completeness: & $28.3^{\circ},>92 \%$ (up to 25.2, $\left.>98 \%\right)$ \\
$N\left(h k l_{\text {measured }}, N(h k l)_{\text {unique }}, R_{\text {int }}:\right.$ & $7165,5242,0.017$ \\
Criterion for $l_{\text {obs }}, N\left(h k l l_{\mathrm{gt}}:\right.$ & $I_{\text {obs }}>2 \sigma\left(I_{\text {obs }}\right), 3332$ \\
$N(\text { param })_{\text {refined }}:$ & 291 \\
Programs: & Bruker programs [1], SHELX [2, 3]
\end{tabular}

tions and a list of the atoms including atomic coordinates and displacement parameters.

\section{Source of material}

The title complex was prepared in by two steps using pyrene as the starting material. The intermediate 1,8-dibromopyrene was prepared through the bromination of pyrene according to the literature [4]. The final product was synthesized as following: $3.38 \mathrm{~g}$ (24 mmol) of $p$-methylthiophenol, $3.60 \mathrm{~g}$ (10 mmol) of 1,8-dibromopyrene and $50 \mathrm{~mL}$ of dimethylformamide were added to a $100 \mathrm{~mL}$ round bottom flask. The above mixture was stirred for $10 \mathrm{~min}$ in an ice bath under the protection of nitrogen atmosphere. Then, $0.96 \mathrm{~g}(24 \mathrm{mmol})$ of $\mathrm{NaH}(60 \%)$ was slowly added to the above flask in batches and the mixture was stirred for another $10 \mathrm{~min}$. After all the generated hydrogen by the reaction was discharged, the mixture was refluxed for $10 \mathrm{~h}$, poured into water, extracted with dichloromethane and washed with water for three times. The organic phase was dried over $\mathrm{MgSO}_{4}$, filtered, and concentrated. The concentrated product was purified by silica gel flash column chromatography using hexane as the eluent. Yield: $3.70 \mathrm{~g}, 86 \%$. The light yellow strip crystals of the title compound were obtained by slow evaporation of hexane $/ \mathrm{CH}_{2} \mathrm{Cl}_{2}$ solution ( $\left.\mathrm{v}: \mathrm{v}=1 / 1\right)$ and the selected suitable single crystal was structurally determined by X-ray diffraction analysis. Melting point: $167-170{ }^{\circ} \mathrm{C} .{ }^{1} \mathbf{H}$ NMR $(400 \mathrm{MHz}$, $\left.\mathrm{CDCl}_{3}\right) \delta$ (TMS, ppm): $8.73(\mathrm{~s}, 2 \mathrm{H}, \mathrm{J}=8.73 \mathrm{~Hz}), 8.13-8.04$ $(\mathrm{m}, 6 \mathrm{H}, \mathrm{J}=8.07 \mathrm{~Hz}), 7.23-7.20$ (m, 4H), 711-7.09 (m, 4H), 2.34 (s, 6H). ${ }^{13}$ C NMR (400 MHz, $\mathrm{CDCl}_{3}$ ), $\delta$ (TMS, ppm): 136.72, 136.67, 133.12, 133.03, 131.61, 131.37, 131.27, 131.23, 131.15, 130.91, 
Table 2: Fractional atomic coordinates and isotropic or equivalent isotropic displacement parameters $\left(\AA^{2}\right)$.

\begin{tabular}{|c|c|c|c|c|}
\hline Atom & $x$ & $y$ & $z$ & $U_{\text {iso }} * / U_{\text {eq }}$ \\
\hline S1 & $0.69740(9)$ & $0.43537(5)$ & $0.37831(6)$ & $0.0770(2)$ \\
\hline S2 & $0.48251(8)$ & $-0.18943(5)$ & $0.18393(5)$ & $0.0644(2)$ \\
\hline $\mathrm{C} 1$ & $0.7442(3)$ & $0.31544(18)$ & $0.45302(19)$ & $0.0594(6)$ \\
\hline C2 & $0.7065(3)$ & $0.20003(17)$ & $0.41316(16)$ & $0.0486(5)$ \\
\hline C3 & $0.6342(3)$ & $0.17104(18)$ & $0.31089(16)$ & $0.0527(5)$ \\
\hline H3 & 0.6129 & 0.2299 & 0.2670 & $0.063^{*}$ \\
\hline C4 & $0.5965(3)$ & $0.05998(18)$ & $0.27694(16)$ & $0.0513(5)$ \\
\hline $\mathrm{H} 4$ & 0.5494 & 0.0445 & 0.2102 & $0.062^{*}$ \\
\hline C5 & $0.6267(3)$ & $-0.03433(16)$ & $0.34018(15)$ & $0.0437(4)$ \\
\hline C6 & $0.5844(3)$ & $-0.15114(17)$ & $0.30759(16)$ & $0.0494(5)$ \\
\hline $\mathrm{C} 7$ & $0.6148(3)$ & $-0.23825(18)$ & $0.37369(18)$ & $0.0570(6)$ \\
\hline $\mathrm{H} 7$ & 0.5850 & -0.3146 & 0.3518 & $0.068^{*}$ \\
\hline C8 & $0.6885(3)$ & $-0.21351(18)$ & $0.47141(18)$ & $0.0569(6)$ \\
\hline $\mathrm{H} 8$ & 0.7081 & -0.2736 & 0.5142 & $0.068^{\star}$ \\
\hline C9 & $0.7345(3)$ & $-0.09992(17)$ & $0.50776(15)$ & $0.0475(5)$ \\
\hline C10 & $0.8112(3)$ & $-0.0710(2)$ & $0.60887(16)$ & .0591(6) \\
\hline $\mathrm{H} 10$ & 0.8349 & -0.1303 & 0.6520 & $0.071 *$ \\
\hline C11 & $0.8494(3)$ & $0.0373(2)$ & $0.64281(17)$ & $.0597(6)$ \\
\hline H11 & 0.8996 & 0.0521 & 0.7089 & $0.072^{\star}$ \\
\hline C12 & $0.8151(3)$ & $0.13233(19)$ & $0.58005(16)$ & $.0525(5)$ \\
\hline C13 & $0.8474(3)$ & $0.2477(2)$ & $0.61509(19)$ & $0.0681(7)$ \\
\hline H13 & 0.8934 & 0.2646 & 0.6819 & $.082^{\star}$ \\
\hline C14 & $0.8129(3)$ & $0.3367(2)$ & $0.5533(2)$ & $0.0710(7)$ \\
\hline H14 & 0.8358 & 0.4128 & 0.5790 & $.085^{\star}$ \\
\hline C15 & $0.7417(2)$ & $0.10833(16)$ & $0.47791(15)$ & $0.0444(5)$ \\
\hline C16 & $0.7012(2)$ & $-0.00876(16)$ & $0.44145(14)$ & $21(4)$ \\
\hline C17 & $0.6594(3)$ & $-0.17370(17)$ & $0.10236(15)$ & $0.0498(5)$ \\
\hline C18 & $0.6241(3)$ & $-0.1441(2)$ & $0.00261(18)$ & $0.0714(7)$ \\
\hline $\mathrm{H} 18$ & 0.5090 & -0.1294 & -0.0200 & $0.086^{*}$ \\
\hline C19 & $0.7594(4)$ & $-0.1363(2)$ & $-0.06414(18)$ & $0.0756(7)$ \\
\hline H19 & 0.7321 & -0.1174 & -0.1310 & $0.091^{*}$ \\
\hline $\mathrm{C} 20$ & $0.9313(3)$ & $-0.15558(19)$ & $-0.03429(16)$ & $0.0582(6)$ \\
\hline $\mathrm{C} 21$ & $0.9657(3)$ & $-0.1832(2)$ & $0.06582(18)$ & $0.0657(6)$ \\
\hline $\mathrm{H} 21$ & 1.0814 & -0.1959 & 0.0888 & $0.079^{\star}$ \\
\hline $\mathrm{C} 22$ & $0.8326(3)$ & $-0.1925(2)$ & $0.13283(18)$ & $0.0625(6)$ \\
\hline $\mathrm{H} 22$ & 0.8605 & -0.2118 & 0.1996 & $0.075^{\star}$ \\
\hline C23 & $1.0778(4)$ & $-0.1467(2)$ & $-0.10675(19)$ & $0.0802(8)$ \\
\hline $\mathrm{H} 23 \mathrm{~A}$ & 1.0299 & -0.1247 & -0.1719 & $0.120^{*}$ \\
\hline $\mathrm{H} 23 \mathrm{~B}$ & 1.1340 & -0.2204 & -0.1157 & 0.120 * \\
\hline $\mathrm{H} 23 \mathrm{C}$ & 1.1627 & -0.0892 & -0.0787 & $0.120^{*}$ \\
\hline $\mathrm{C} 24$ & $0.8800(3)$ & $0.43790(17)$ & $0.29878(18)$ & $0.0591(6)$ \\
\hline $\mathrm{C} 25$ & $0.8680(4)$ & $0.5036(2)$ & $0.2140(2)$ & $0.0793(8)$ \\
\hline $\mathrm{H} 25$ & 0.7641 & 0.5418 & 0.1979 & $0.095^{*}$ \\
\hline C26 & $1.0101(5)$ & $0.5128(2)$ & $0.1532(2)$ & $0.0850(8)$ \\
\hline $\mathrm{H} 26$ & 0.9991 & 0.5577 & 0.0970 & $0.102^{\star}$ \\
\hline C27 & $1.1676(4)$ & $0.4578(2)$ & $0.1727(2)$ & $0.0762(7)$ \\
\hline C28 & $1.1762(4)$ & $0.3923(2)$ & $0.2574(2)$ & $0.0744(7)$ \\
\hline $\mathrm{H} 28$ & 1.2797 & 0.3534 & 0.2731 & $0.089 *$ \\
\hline C29 & $1.0360(3)$ & $0.3826(2)$ & $0.3194(2)$ & $0.0662(6)$ \\
\hline H29 & 1.0474 & 0.3381 & 0.3759 & $0.079 *$ \\
\hline C30 & $1.3222(5)$ & $0.4690(3)$ & $0.1057(3)$ & $0.1110(11)$ \\
\hline $\mathrm{H} 30 \mathrm{~A}$ & 1.3135 & 0.5401 & 0.0720 & $0.166^{*}$ \\
\hline $\mathrm{H} 30 \mathrm{~B}$ & 1.3210 & 0.4046 & 0.0553 & $0.166^{*}$ \\
\hline $\mathrm{H} 30 \mathrm{C}$ & 1.4301 & 0.4695 & 0.1475 & $0.166^{*}$ \\
\hline
\end{tabular}

130.60, 130.47, 130.25, 130.12, 130.05, 128.14, 127.63, 125.57, 125.48, 125.18, 125.03, 21.07. MALDI-TOF MS (m/z): calcd. for $\mathrm{C}_{30} \mathrm{H}_{22} \mathrm{~S}_{2}$ 446.1, found 446.1. Elemental analysis-calculated for $\mathrm{C}_{30} \mathrm{H}_{22} \mathrm{~S}_{2}$ : C, $80.68 \%$;, $4.96 \%$;, $14.36 \%$; found: C, $80.54 \%$, H, 4.98\%; S, $14.28 \%$.

\section{Experimental details}

All $\mathrm{H}$ atoms were introduced using the HFIX command in the SHELXL-2014 program [2], with the value of $0.93 \AA$ or $0.96 \AA$ for $\mathrm{C}-\mathrm{H}$ bond distances. All $\mathrm{H}$ atoms were refined as riding with $U_{\text {iso }}(\mathrm{H})=1.2 U_{\text {eq }}(\mathrm{C})$ for aromatic or $U_{\text {iso }}(\mathrm{H})=1.5 U_{\text {eq }}(\mathrm{C})$ for methyl $\mathrm{H}$ atoms, respectively. The structure was checked using PLATON [5].

\section{Comment}

Up to date, a large number of new organic compounds with interesting optical, electronic, magnetic, biological and bifunctional as well as mutifunctional properties have been designed, synthesized and characterized. However, the precursors of these many organic compounds are relatively limited. Pyrene, a widely used precursor, and its derivatives have attracted considerable attention because their actual use or potential as organic light-emitting diodes (OLED), organic field effect transistor (OFET), organic lasers, chemosensors and solar cells, etc. [6-13]. Among the many pyrene-based compounds, the design and synthesis of organic sulfurcontaining compounds have also attracted attention because they may exhibit interesting properties originating from the their electronic structure. For instance, the introduction of a thioether group could make them useful as peroxide sensors. Up to date, there are very limited reports of the crystal structures of pyrene-based thioether compounds [14-16]. Recently, we have reported the crystal strucure of the 1,3,6,8-tetrakis ( $p$ tolylthio)pyrene [16]. Herein, we report the synthesis, crystal structure of a new pyrene-based thioether 1,8-bis( $p$-tolylthio) pyrene. In addition, preliminary study indicates that the title compound could be a potential sensor for peroxides such as $m$-chloroperoxybenzoic acid.

In the molecular structure of the title compound, the two $p$-tolylthio groups are located on the same side of the pyrene ring. The main pryene core together with the two sulfur atoms are almost coplanar and the largest deviation from the main plane is 0.064(3) A. The dihedral angle between the pyrene and two benzene rings are $85.9(3)^{\circ}$ and $88.0(3)^{\circ}$, respectively. The dihedral angle between the two benzene rings is $22.6(3)^{\circ}$. The $\mathrm{C}-\mathrm{S}$ bond distances in the title compound are very similar and distributed in a very narrow range of $1.779(2)-1.783(3) \AA$. The two $\mathrm{C}-\mathrm{S}-\mathrm{C}$ bond angles are very similar, with $102.77(11)^{\circ}$ for $\mathrm{C} 1-\mathrm{S} 1-\mathrm{C} 24$ and 


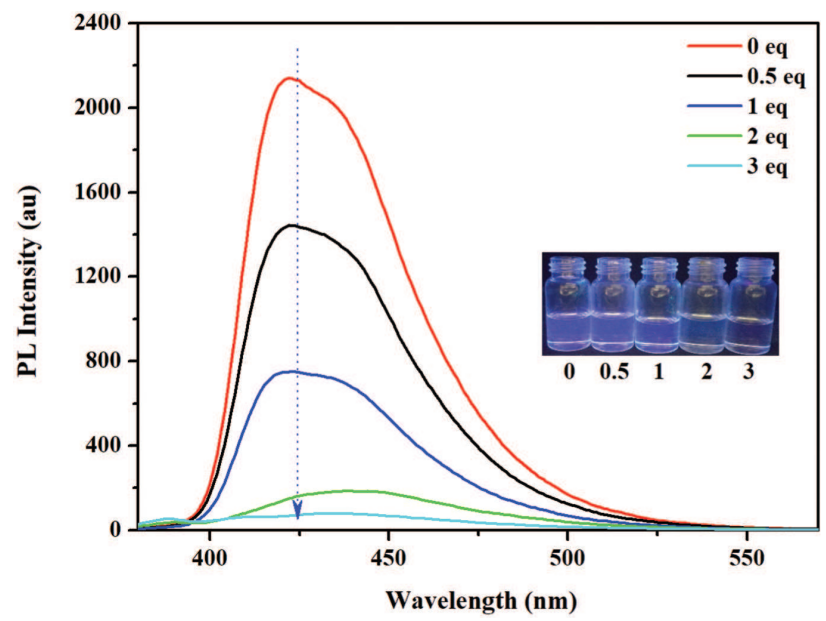

Figure 1: PL spectra of 1,8-bis( $p$-tolylthio)pyrene in DCM in the presence of different content of $m$-chloroperoxybenzoic acid from 0 to 3 eq. For PL measurement, 1,8-bis( $p$-tolylthio)pyrene concentration: $10^{-5} \mathrm{M}$, excitation wavelength: $365 \mathrm{~nm}$.

102.34(10) ${ }^{\circ}$ for $\mathrm{C} 6-\mathrm{S} 2-\mathrm{C} 17$. The $\mathrm{C}-\mathrm{S}$ bond distances and $\mathrm{C}-\mathrm{S}-\mathrm{C}$ bond angles are within normal ranges and comparable to those found in 1,3,6,8-tetrakis( $p$-tolylthio) pyrene [16]. The molecules of the title compound form a onedimensional supramolecular structure by intermolecular $\pi-$ $\pi$ (pyrene) interactions. These one-dimensional supramolecular structures are linked together into three-dimensional supramolecular structure by intermolecular $\mathrm{C}-\mathrm{H} \cdots \pi$ and $\mathrm{C}-\mathrm{H} \cdot \mathrm{*S}$ interactions.

When the title compound was dissolved in DCM, a set of absorption peaks from 325 to $425 \mathrm{~nm}$ and a emission peak around $425 \mathrm{~nm}$ for the solution was observed. Interestingly, 1,8-bis( $p$-tolylthio)pyrene exhibits potential application in detection of peroxides such as $m$-chloroperoxybenzoic acid. The emission of 1,8 -bis( $p$-tolylthio)pyrene in DCM is blue. When adding $m$-chloroperoxybenzoic acid to the DCM solution of 1,8-bis(p-tolylthio)pyrene at room temperature, the emission intensity declines drastically, as shown in Figure 1 . When the molar ratio of $m$-chloroperoxybenzoic acid/1,8-bis( $p$-tolylthio)pyrene reaches $2: 1$, the emission is very weak. Throughout the process, the title compound displays an "on-off” optical switching property evident as an emission change from blue to colorless with the addition of $m$-chloroperoxybenzoic into its DCM solution. The color change is probably due to the presence of the thioether group which can be easily oxidized by $m$-chloroperoxybenzoic acid, yielding a sulfoxide compound which does not emit fluorescence. The present results at least indicates that the title compound could be employed as one effective sensor for the quality control or effective ingredient detection of $m$-chloroperoxybenzoic. More detailed investigations of the selectivity and sensitivity of this potential sensor will be carried out in the future.

Acknowledgements: This work was funded by the open research fund program of Shandong Provincial Key Laboratory of Oilfield Produced Water Treatment and Environmental Pollution Control (Sinopec Petroleum Engineering Corporation).

\section{References}

1. Bruker. APEX3, SAINT-Plus, XPREP. Bruker AXS Inc., Madison, WI, USA (2016)

2. Sheldrick, G. M.: Crystal structure refinement with SHELXL. Acta Crystallogr. C71 (2015) 3-8.

3. Sheldrick, G. M.: A short history of SHELX. Acta Crystallogr. A64 (2008) 112-122.

4. Grimshaw, J.; Trocha-Grimshaw, J.: Characterisation of 1,6and 1,8-dibromopyrenes. J. Chem. Soc. Perkin. Trans. 1 (1972) 1622-1623.

5. Spek, A. L.: Structure validation in chemical crystallography. Acta Crystallogr. D65 (2009) 148-155.

6. Zhang, R.; Sun, H.; Zhao,Y.; Tang, X. X.; Ni, Z. H.: Dipolar 1,3,6,8-tetrasubstituted pyrene-based blue emitters containing electro-transporting benzimidazole moieties: syntheses, structures, optical properties, electrochemistry and electroluminescence. Dyes Pigm. 152 (2018) 1-13.

7. Figueira-Duarte, T. M.; Mullen, K.: Pyrene-based materials for organic electronics. Chem. Rev. 111 (2011) 7260-7314.

8. Zhang, R.; Zhao, Y.; Zhang, L. F.; Xu, L.; Ni, Z. H.: A series of short axially symmetrically $1,3,6,8$-tetrasubstituted pyrenebased green and blue emitters with 4-tert-butylphenyl and aryamine attachments. Dyes Pigm. 130 (2016) 106-115.

9. Yi, J. P.; Zhao, L.; Xu, W. D.; Liu, C. F.; Lai, W. Y.; Huang, W.: Pyrene-capped starburst emitters as gain media for organic lasers: design, synthesis, and stabilized lasing properties. J. Mater. Chem. C. 4 (2016) 7546-7553.

10. Chu, K. H.; Zhou, Y.; Fang, Y.; Wang, L. H.; Li, J. Y.; Yao, C.: Rhodamine-pyrene conjugated chemosensors for ratiometric detection of $\mathrm{Hg}^{2+}$ ions: different sensing behavior between a spirolactone and a spirothiolactone. Dyes Pigm. 98 (2013) 339-346.

11. Liu, X.; Luo, G. P.; Cai, X. Y.; Wu, H. B.; Su, S. J.; Cao, Y.: Pyrene terminal functionalized perylene diimide as non-fullerene acceptors for bulk heterojunction solar cells. RSC Adv. 5 (2015) 83155-83163.

12. Liu, Y. F.; Jun, E. J.; Kim, G.; Lee, A. R.; Lee, J. H.; Yoon, J.: A bispyrene derivative as a selective fluorescent probe for RNA. Chem. Commun. 50 (2014) 2505-2507.

13. Gingras, M.; Placide, V.; Raimundo, J. M.; Bergamini, G.; Ceroni, P.; Balzani, V.: Polysulfurated pyrene-cored dendrimers: luminescent and electrochromic properties. Chem. Eur. J. 14 (2008) 10357-10363.

14. Lee, S.; Chen, B. L.; Fredrickson, D. C.; DiSalvo, F. J.; Lobkovsky, E.; Adams, J. A.: Crystal structures of (pyrene) ${ }_{10}$ $\left(\mathrm{I}_{3}{ }^{-}\right)_{4}\left(\mathrm{I}_{2}\right)_{10}$ and $[1,3,6,8 \text {-tetrakis(methylthio)pyrene }]_{3}\left(\mathrm{I}_{3}{ }^{-}\right)_{3}\left(\mathrm{I}_{2}\right)_{7}$ : 
structural trends in fused aromaticpolyiodides Chem. Mater. 115 (2003) 1420-1433.

15. Oniwa, K.; Kikuchi, H.; Shimotani, H.; Ikeda, S.; Asao, N.; Yamamoto, Y.; Tanigaki, K.; Jin, T. N.: 2-Positional pyrene end-capped oligothiophenes for high performance organic field effect transistors. Chem. Commun. 52 (2016) 4800-4803.

16. Xu, L. H.; Ni, Z. H.: Crystal structure of 1,3,6,8-tetrakis ( $p$ tolylthio) pyrene, $\mathrm{C}_{44} \mathrm{H}_{34} \mathrm{~S}_{4}$. Z. Kristallogr. NCS 231 (2016) 255-257. 